\title{
PENYULUHAN PROGRAM LITERASI INFORMASI KESEHATAN DALAM MENINGKATKAN KUALITAS SANITASI BAGI MASYARAKAT DI KAKI GUNUNG BURANGRANG KAB. BANDUNG BARAT
}

\author{
COUNSELING INFORMATION LITERACY PROGRAM IN IMPROVING THE \\ QUALITY OF HEALTH SANITATION OF THE PEOPLE IN THE FOOT MOUNT \\ BURANGRANG KAB. WEST BANDUNG
}

\author{
${ }^{1)}$ Ditha Prasanti, ${ }^{2)}$ Ikhsan Fuady \\ ${ }^{1,2)}$ Fakultas Ilmu Komunikasi Universitas Padjadjaran \\ Jl.Raya Bandung - Sumedang KM 21 Jatinangor, Bandung \\ Email: dithaprasanti@gmail.com \\ sandyca@yahoo.co.id
}

\begin{abstract}
ABSTRAK
Kemampuan masyarakat dalam mengakses kebutuhan informasi masih belum merata antara masyarakat yang tinggal di perkotaan dengan masyarakat yang tinggal di pedesaan. Kemampuan mengakses informasi adalah pintu awal yang harus terbuka untuk dapat mengolah dan memahami informasi, khususnya dalam hal ini adalah informasi kesehatan. Sanitasi merupakan salah satu komponen dari kesehatan lingkungan, yaitu perilaku yang disengaja untuk membudayakan hidup bersih untuk mencegah manusia bersentuh langsung dengan kotoran dan bahan buangan berbahaya lainnya, dengan harapan dapat menjaga dan meningkatkan kesehatan manusia. Oleh karena itu, penulis melakukan kegiatan Pengabdian Kepada Masyarakat yang berjudul "Penyuluhan Program Literasi Informasi Kesehatan dalam Meningkatkan Kualitas Sanitasi bagi Masyarakat di kaki Gunung Burangrang Kab.Bandung Barat.”. Kegiatan Pengabdian Kepada Masyarakat ini memiliki tujuan dapat menghasilkan luaran yaitu: 1) Memberikan pengetahuan dan wawasan yang konkret mengenai literasi informasi kesehatan dalam meningkatkan kualitas sanitasi bagi masyarakat di Kabupaten Bandung Barat; 2) Memberikan pengetahuan dan wawasan menyeluruh mengenai mengenai literasi informasi kesehatan dalam meningkatkan kualitas sanitasi bagi masyarakat di Kabupaten Bandung Barat. Metode pelaksanaan PKM yang dilakukan dalam kegiatan penyuluhan ini adalah metode ice breaking; metode workshop, ceramah, dan kaji tindak.
\end{abstract}

Kata Kunci: Penyuluhan, Literasi, Informasi, Kesehatan, Sanitasi, Bandung Barat

\section{ABSTRACT}

The ability of the community to access information needs is still uneven among urban people and rural communities. The ability to access information is an open door that must be open to be able to process and understand information, especially in this case is health information. Sanitation is one component of environmental health, a deliberate behavior to civilize a clean life to prevent humans directly touched with dirt and other hazardous waste materials, in the hope of maintaining and improving human health. Therefore, the authors perform Community Service activities entitled "Health Information Literacy Program Counseling in Improving the Quality of Sanitation for the Community at the foot of Mount Burangrang Kab. Bandung Barat." Community Service Activities has a purpose to produce outcomes, namely: 1) Provide concrete knowledge and insight about health information literacy in improving the quality of sanitation for people in West Bandung regency; 2) Providing comprehensive knowledge and insight about health information literacy 
Ditha Prasanti, Ikhsan Fuady

Penyuluhan Program Literasi Informasi Kesehatan Dalam Meningkatkan Kualitas Sanitasi Bagi

Masyarakat Di Kaki Gunung Burangrang Kab. Bandung Barat

in improving the quality of sanitation for people in West Bandung Regency. Method of PKM implementation conducted in this extension activity is ice breaking method; Workshop methods, lectures, and action studies.

Keywords: Counseling, Literacy, Information, Health, Sanitation, West Bandung

Submited : 10 April 2017 Revision : 20 Juni 2017 Accepted:9 September 2017

\section{PENDAHULUAN}

Literasi informasi merupakan hal yang sangat penting dimiliki oleh setiap individu. Ada beberapa bidang literasi informasi, salah satunya adalah literasi informasi kesehatan. Jika kita cermati, literasi informasi kesehatan yang berada pada ranah pengguna layanan kesehatan, yaitu masyarakat pada umumnya, sering menjadi masalah yang terabaikan. Kemampuan masyarakat untuk dapat mengakses informasi saja masih belum merata antara masyarakat yang tinggal di perkotaan dengan masyarakat yang tinggal di pedesaan. Kemampuan mengakses informasi adalah pintu awal yang harus terbuka untuk dapat mengolah dan memahami informasi, khususnya dalam hal ini adalah informasi kesehatan.

Sanitasi merupakan salah satu komponen dari kesehatan lingkungan, yaitu perilaku yang disengaja untuk membudayakan hidup bersih untuk mencegah manusia bersentuh langsung dengan kotoran dan bahan buangan berbahaya lainnya, dengan harapan dapat menjaga dan meningkatkan kesehatan manusia.

Berdasarkan data yang dilansir dari www.unicef.org, penyakit diare masih merupakan penyebab utama kematian anak berusia di bawah lima tahun di Indonesia. Laporan Riskesdas 2007 menunjukkan diare sebagai penyebab

31 persen kematian anak usia antara 1 bulan hingga satu tahun, dan 25 persen kematian anak usia antara satu sampai empat tahun. Angka diare pada anak-anak dari rumah tangga yang menggunakan sumur terbuka untuk air minum tercatat 34 persen lebih tinggi dibandingkan dengan anak-anak dari rumah tangga yang menggunakan air ledeng, Selain itu, angka diare lebih tinggi sebesar 66 persen pada anak-anak dari keluarga yang melakukan buang air besar di sungai atau selokan dibandingkan mereka pada rumah tangga dengan fasilitas toilet pribadi.

Sanitasi dan kebersihan lingkungan di Indonesia masih memprihatinkan, khususnya di kawasan desa Cimanggu yang dekat lokasinya dengan kaki gunung Burangrang. Sebagai daerah yang rawan bencana alam, masyarakat di kawasan desa Cimanggu harus memiliki literasi informasi kesehatan yang baik dalam meningkatkan kualitas sanitasi dan kebersihan lingkungannya.

Berdasarkan data yang dilansir dari Riskesdas, belum optimalnya sanitasi di Indonesia ini ditandai dengan masih tingginya angka kejadian penyakit infeksi dan penyakit menular di masyarakat. Pada saat negara lain pola penyakit sudah bergeser menjadi penyakit degeneratif, Indonesia masih direpotkan oleh kasus demam berdarah, Diare, Kusta, serta Hepatitis A (Depkes RI: 2013).

Menurut World Health Organization (WHO), kondisi dan perilaku sanitasi yang baik dan perbaikan kualitas air minum dapat menurunkan kasus diare yang akan mengurangi jumlah hari tidak masuk sekolah dan tidak masuk kerja hingga 8 hari pertahun atau meningkat $17 \%$ yang tentunya berdampak pada kesempatan meningkatkan pendapatan (WHO: 2013). 
Sanitasi sangat menentukan keberhasilan dari paradigma pembangunan kesehatan lingkungan lima tahun ke depan yang lebih menekankan pada aspek pencegahan dari aspek pengobatan. Dengan adanya upaya pencegahan yang baik, angka kejadian penyakit yang terkait dengan kondisi lingkungan dapat dicegah. Selain itu anggaran yang diperlukan untuk preventif juga relatif lebih terjangkau daripada melakukan upaya pengobatan. Sanitasi dan kebersihan lingkungan menjadi hal yang sangat penting dilakukan pasca bencana longsor yang terjadi di kaki gunung Burangrang.

Upaya penerapan sanitasi dan kebersihan lingkungan juga dapat dilakukan jika masyarakat memiliki tingkat literasi informasi kesehatan yang tinggi. Tetapi faktor minat baca masyarakat yang rendah, ditambah dengan tingkat pendidikan yang rendah menjadi penyebab tidak efektifnya upaya penyebarluasan informasi kesehatan. Berdasarkan hal tersebut, tentu diperlukan kegiatan Pengabdian Kepada Masyarakat ini. Hal tersebut memperkuat kami untuk mengangkat program penyuluhan dengan topik "Penyuluhan Program Literasi Informasi Kesehatan dalam meningkatkan kualitas Sanitasi Pasca Bencana Longsor di kaki Gunung Burangrang Kab.Bandung Barat”.

Dalam kegiatan Pengabdian Kepada Masyarakat ini, program ini dibuat sejalan dengan penelitian yang kami lakukan, yaitu tentang mitigasi bencana dan penanggulangan sanitasi pasca bencana longsor. Program ini merupakan tindak lanjut dari dampak permasalahan penelitian yang dilakukan, sebagai strategi untuk menumbuhkan kesadaran memiliki literasi informasi kesehatan.

Berdasarkan permasalahan tersebut di atas, tentu menjadi penting agar masyarakat memiliki pengetahuan tentang "program peningkatan literasi informasi kesehatan" demi menunjang pembangunan kesehatan di desa Cimanggu yang berada pada kawasan kaki gunung Burangrang, kab.Bandung Barat.

\section{KAJIAN LITERATUR}

\section{Literasi Kesehatan}

Literasi kesehatan meliputi kapasitas masyarakat, keterampilan, pengetahuan dan motivasi untuk mengakses, memahami, menilai dan menerapkan informasi kesehatan dalam bentuk yang berbeda, untuk membentuk penilaian dan penambilan keputusan dalam hal menggunakan sistem pelayanan kesehatan, pencegahan penyakit dan promosi kesehatan, untuk meningkatkan kualitas hidup sepanjang perjalanan kehidupannya. (European Health Literacy Consortium: 2013).

Konsep literasi kesehatan muncul dalam kaitannya dengan pendidikan kesehatan pada tahun 1970 di Amerika Serikat dan ketertarikan terhadap topik ini telah meningkat dengan pesat sejak tahun 1990. Literasi kesehatan telah diakui sebagai salah satu determinan kesehatan dan menjadi salah satu goal pembangunan kesehatan masyarakat (Nutbeam, 2000). Literasi kesehatan adalah kemampuan untuk mendapatkan, memproses, dan memahami informasi kesehatan dasar dan pelayanan kesehatan yang bertujuan untuk membuat keputusan kesehatan yang tepat, telah berkembang menjadi kontributor status kesehatan (Nutbeam, 2000).

Literasi kesehatan umumnya dikaitkan dengan kemampuan membaca dan menulis seseorang. Hal ini sesuai dengan definisi literasi kesehatan yang dinyatakan oleh The American Medical Association yang mewakili model biomedis sebagai kemampuan membaca dan memahami resep obat, kartu berobat dan bentuk materi lainnya yang berhubungan dengan peran dirinya sebagai pasien. Sedangkan WHO yang mengarah pada model biopsikososial mendefinisikan literasi kesehatan sebagai keterampilan kognisi dan 
sosial yang menentukan motivasi dan kemampuan individu untuk mengakses, memahami dan menggunakan informasi sebagai cara untuk meningkatkan dan menjaga kesehatannya (Berry, 2007: 62).

Hampir senada dengan pernyataan sebelumnya, Zarcadoolas dkk (2006) mendefinisikan literasi kesehatan sebagai, the wide range of skills and competencies that people develop to seek out, comprehend, evaluate, and use health information and concepts to make informed choices, reduce health risks, and increase quality of life. Kedua definisi di atas menambahkan dampak yang ditimbulkan dari literasi kesehatan terhadap kualitas hidup seseorang. Masih dalam Berry, Doak dkk, literasi kesehatan didefinisikan sebagai gambaran kognisi seseorang yang berkontribusi terhadap kemampuan berbicara secara fasih dan kemampuan memaknai kata-kata, kemampuan membaca cepat sehingga dapat menangkap kata kunci dalam informasi visual, dan dapat memilih hal-hal yang penting dari sebuah informasi, dan dapat memahami dan menginterpretasikan angka angka (Berry, 2007:62).

Selanjutnya The National Library of Medicine's (NLM) dan Institute of Medicine (IOM) mendefinisikan literasi kesehatan "the degree to which an individuals have the capacity to obtain, process and understand basic health information and services needed to make appropriate health decisions " (Ratzan dan Parker dalam Nielsen-Bohlman, 2004). Yang menarik dari definisi tersebut adalah adanya tambahan "It consists of four components (a) cultural and conceptual knowledge, (b) oral literacy, (c) print literacy, and $(d)$ numeracy.

Namun demikian, literasi kesehatan belum dikenal di Indonesia, bahkan cukup sulit menerjemahkan istilah ini ke dalam bahasa indonesia. Literasi kesehatan juga menggambarkan kemampuan kognitif dan ketrampilan sosial yang dapat diartikan sebagai mativasi dan kemampuan individu untuk mengakses, memahami dan menggunakan informasi dalam hal menjaga kesehatnnya. Literasi kesehatan lebih dari sekedar kemampuan membaca pamflet dan kesuksesan berhubungan atau berkomunikasi dengan petugas kesehatan. Dengan meningkatkan kemampuan akses terhadap informasi dan kapasitas untuk menggunakannya secara efektif, health literacy adalah variabel penting untuk memberdayakan individu dalam hal kesehatan (Nutbeam, 2000).

Penulis memilih kader PKK dan kader Posyandu sebagai bagian dari masyarakat di kawasan desa Cimanggu, yang lokasinya dekat dengan kaki Gunung Burangrang. Berdasarkan pemaparan dari Ibu Kepala Desa Cimanggu, peran kader sangat besar dalam menyelesaikan segala masalah yang terjadi di desa Cimanggu. Masyarakat desa Cimanggu sangat memerlukan wawasan pengetahuan tentang sanitasi dan kebersihan lingkungan. Hal ini adalah salah satu alasan penulis merasa memiliki tanggung jawab untuk memberikan wawasan dan kesadaran akan hal tersebut.

\section{TUJUAN DAN MANFAAT PKM}

Kegiatan Pengabdian Kepada Masyarakat yang dilakukan oleh tim akademisi Prodi Ilmu Komunikasi Universitas Padjadjaran memiliki target sebagai berikut:

1.Masyarakat di desa Cimanggu Kabupaten Bandung Barat menyadari pentingnya memiliki kemampuan dan pemahaman tentang literasi informasi kesehatan dalam meningkatkan kualitas sanitasi dan kebersihan lingkungan

2.Masyarakat di desa Cimanggu Kabupaten Bandung Barat memahami langkah-langkah 
yang harus diambil berkaitan dengan literasi informasi kesehatan dalam meningkatkan kualitas sanitasi dan kebersihan lingkungan.

3.Masyarakat di desa Cimanggu Kabupaten Bandung Barat memiliki kemampuan untuk menerapkan program literasi informasi kesehatan dalam meningkatkan kualitas sanitasi dan kebersihan lingkungan.

\section{METODE PELAKSANAAN PKM}

Kegiatan penyuluhan literasi informasi kesehatan tentang sanitasi dan kebersihan lingkungan yang akan dilakukan ini, dengan mempertimbangkan materi penyuluhan, masyarakat sebagai audiens, masalah yang berkembang dan lingkungan yang mendukung, dalam pelaksanaannya akan menggunakan beberapa metode berikut :

1) Metode workshop, dengan penayangan materi "Program literasi kesehatan dalam meningkatkan kualitas sanitasi pasca bencana longsor" menggunakan media audio visual. Metode ini lebih menarik karena disampaikan dengan gambar dan narasi serta musik yang menarik dan menjadikan materi lebih mudah diterima oleh masyarakat.

2) Metode ceramah dan pendampingan, dengan memberikan wawasan umum kepada masyarakat mengenai program literasi informasi kesehatan tentang sanitasi dan kebersihan lingkungan. Selain itu, juga memotivasi dan menimbulkan kesadaran masyarakat untuk menjaga sanitasi dan kebersihan lingkungan.

3) Metode kaji tindak, kami akan bermitra dengan pihak dinas kesehatan atau layanan terkait, dengan memberikan kesempatan kepada masyarakat untuk menyampaikan pertanyaan seputar materi yang belum atau tidak dipahaminya, atau pertanyaan di luar materi tapi masih relevan dengan topik yang disampaikan, lalu narasumber yang ahli akan menindaklanjuti masalah tersebut.

\section{HASIL DAN PEMBAHASAN Hasil yang Dicapai}

Kegiatan Pengabdian Kepada Masyarakat (PKM) ini berjalan dengan efektif dan efisien. Kepala Desa Cimanggu sangat mendukung dengan diselenggarakannya kegiatan PKM yang bertemakan tentang "Penyuluhan Literasi informasi kesehatan dalam meningkatkan kualitas sanitasi bagi Masyarakat di kaki Gunung Burangrang kab.Bandung Barat". Menurut pemaparan dari Kepala Desa, sanitasi dan kebersihan lingkungan belum merata dirasakan oleh warga desa tersebut. Hal ini dikarenakan masih kurangnya kesadaran masyarakat tentang pentingnya menjaga sanitasi dan kebersihan lingkungannya.

Berdasarkan hasil survey yang kami lakukan, Kepala Desa pun sepakat agar kegiatan PKM ini dilakukan di Balai Desa saja lalu mengundang para warga, khususnya ibu-ibu kader PKK yang berperan penting dalam segala kegiatan di desa Cimanggu.

Ketika kami menyampaikan penyuluhan pun, mereka sangat antusias menyimaknya. Ada juga peserta yang kembali bercerita tentang pengalamannya berkenaan dengan sanitasi dan kebersihan lingkungan di rumahnya. Para peserta penyuluhan sangat berterima kasih karena mereka merasa telah mendapatkan informasi berharga, dari tips-tips kecil yang kami berikan, berkenaan dengan kegiatan penyuluhan informasi kesehatan dalam bidang komunikasi kesehatan ini. 


\section{Pemaparan Materi Penyuluhan}

Keberadaan air bersih dan sanitasi layak merupakan kebutuhan dasar dan pokok bagi manusia. Ini adalah salah satu point dalam tujuan pembangunan berkelanjutan (Sustainable Development Goals/SDGs) pada sektor lingkungan hidup, yaitu untuk memastikan masyarakat mencapai akses universal air bersih dan sanitasi.

Fokus utama ada pada ketersediaan pangan, air bersih, dan energi yang merupakan dasar dari kehidupan. Perubahan yang paling penting dalam konsumsi berkelanjutan dan produksi akan didorong oleh teknologi, inovasi, desain produk, pedoman kebijakan yang terperinci, pendidikan, dan perubahan perilaku. Sanitasi, begitu juga air bersih, secara khusus dibahas pada tujuan enam SDGs, walaupun tetap perlu menjadi catatan bahwa tujuan-tujuan yang ada ini sesungguhnya merupakan suatu kesatuan.

Penulis juga menyampaikan tentang pentingnya program literasi informasi kesehatan dalam meningkatkan kualitas sanitasi di desa Cimanggu, dengan memaparkan gambar berikut ini.

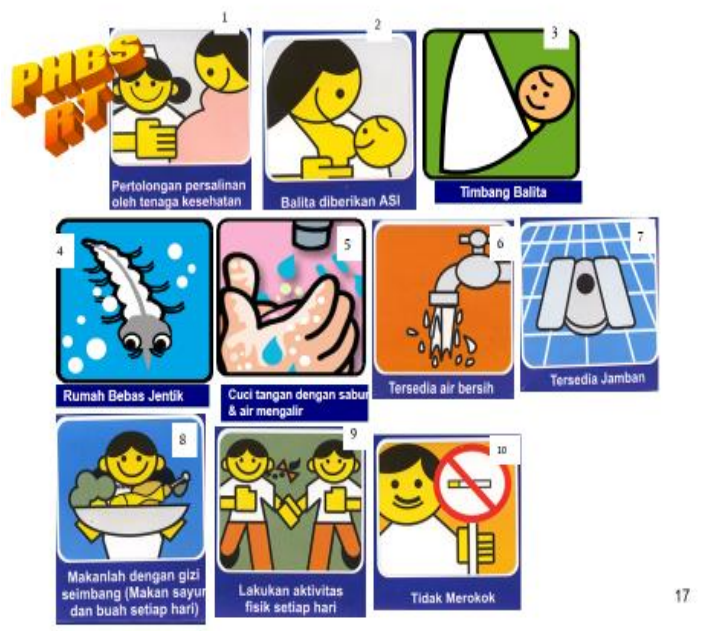

Gambar 1.1

\section{Deskripsi Singkat Pentingnya Sanitasi dan Kebersihan Lingkungan untuk Peserta Penyuluhan}

Selanjutnya, penulis juga memaparkan tentang pentingnya penyuluhan program literasi informasi kesehatan ini untuk meningkatkan kualitas sanitasi dan kebersihan lingkungan di desa Cimanggu.

Penulis berkoordinasi dengan mahasiswa dalam melaksanakan kegiatan PKM ini. Pada sesi pertama, pembukaan acara dilakukan untuk meresmikan berjalannya kegiatan PKM. Kegiatan PKM ini juga melibatkan mahasiswa Prodi Ilmu Komunikasi. Lalu penulis mulai menyampaikan materi penyuluhan kepada para Ibu PKK sebagai peserta mayoritas yang juga berperan sebagai kader di desa Cimanggu.

Jika dilihat pada gambar 1.1, penulis menceritakan perkembangan sanitasi sebagai bagian dari perilaku hidup bersih dan sehat. Oleh karena itu, dalam penyuluhan ini, penulis memilih materi tentang literasi informasi kesehatan dalam meningkatkan kualitas sanitasi dan kebersihan lingkungan, khususnya di kab.Bandung Barat. 


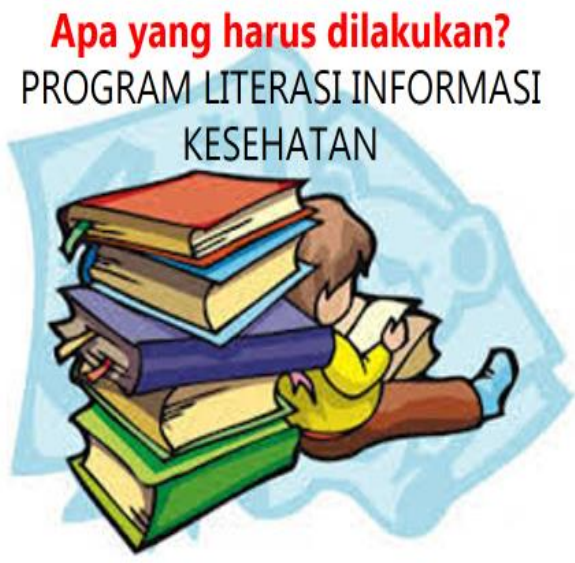

Gambar 1.2

Materi Penyuluhan tentang Program Literasi Informasi Kesehatan untuk Peserta

Berdasarkan gambar di atas, penulis juga mengajak peserta penyuluhan agar memahami pentingnya memiliki program literasi informasi kesehatan. Penulis berusaha menyadarkan peserta penyuluhan agar peduli dengan sanitasi dan kebersihan lingkungan. Oleh karena itu, pada sesi awal penyampaian materi penyuluhan, penulis memberikan data yang signifikan tentang dampak dari sanitasi yang buruk. Setelah itu, penulis baru memberitahu upaya yang perlu dilakukan dalam menjaga sanitasi lingkungan adalah dengan memiliki literasi informasi kesehatan yang baik.

Literasi informasi juga memberikan kemampuan berpikir secara kritis dan logis serta tidak mudah percaya terhadap informasi yang diperoleh dan mengevaluasi informasi yang diperoleh terlebih dahulu sebelum digunakan.

UNESCO (2008: 1) menyatakan bahwa literasi informasi memberikan kemampuan seseorang untuk menafsirkan informasi sebagai pengguna informasi dan menjadi penghasil informasi bagi dirinya sendiri.
UNESCO juga menyatakan bahwa tujuan literasi informasi sebagai berikut:

1. Memberikan keterampilan seseorang agar mampu mengakses dan memperoleh informasi mengenai kesehatan, lingkungan, pendidikan, pekerjaan mereka, dan lain-lain.

2.Memandu mereka dalam membuat keputusan yang tepat mengenai kehidupan mereka.

3.Bertanggung jawab terhadap kesehatan dan pendidikan mereka.

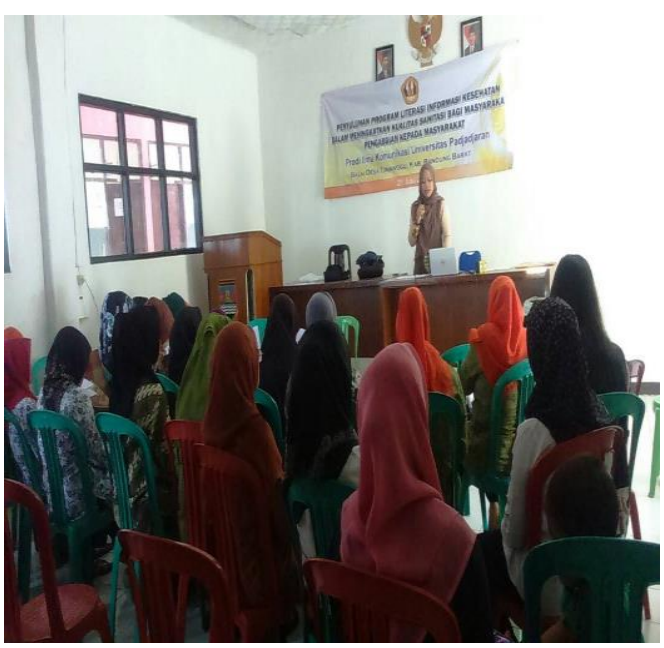

Gambar 1.3

Tim PKM sedang memberikan penyuluhan kepada Peserta di Balai Desa Cimanggu, kaki Gunung Burangrang Kab.Bandung Barat

Penulis menyadarkan peserta penyuluhan, para kader PKK agar aktif dalam mencari informasi kesehatan yang mendukung dalam meningkatkan kualitas sanitasi dan kebersihan lingkungan di desa Cimanggu. Literasi informasi kesehatan ini akan dimiliki oleh siapapun yang mencarinya, salah satunya adalah menjalin kerjasama dengan tenaga medis, seperti: Dokter, Perawat, Bidan, atau Mantri yang akses lokasinya mudah dijangkau. Hal ini penting agar kita bisa 
mengecek informasi kesehatan yang meragukan atau bersifat hoax saja.

Penulis juga menjelaskan dalam penyuluhan bahwa para ibu PKK harus aktif dalam mencari informasi kesehatan, bertanya langsung kepada orang yang ahli di bidangnya, adalah langkah yang tepat dalam mengembangkan program literasi informasi kesehatan ini. Para ibu PKK ini perannya sebagai kader sangat penting dan dibutuhkan oleh masyarakat. Ketika mereka mendengar pernyataan tersebut, penulis melihat ekspresi para peserta yang tergugah. Ada juga peserta yang berani memberikan pendapatnya bahwa dia merasa termotivasi sebagai kader PKK untuk mengembangkan kompetensi diri agar berguna bagi masyarakat di desa Cimanggu tersebut.

Jika peserta penyuluhan sudah menyadari pentingnya menjaga sanitasi dan kesehatan lingkungan, maka otomatis perilaku dalam meningkatkan kualitas sanitasi pun akan terealisasi dengan baik.

\section{Rencana Keberlanjutan Program}

Berdasarkan hasil kegiatan Pengabdian Kepada Masyarakat (PKM) yang telah dilakukan ini, penulis sangat tertarik untuk melanjutkan program PKM ini di kampungkampung lain di Kab.Bandung Barat, khususnya yang masih memiliki kondisi sanitasi yang kurang baik. Antusiasme para peserta penyuluhan juga sangat memotivasi penulis dalam melakukan kegiatan PKM ini. Hal ini bisa terlihat pada gambar 1.4 di bawah ini.

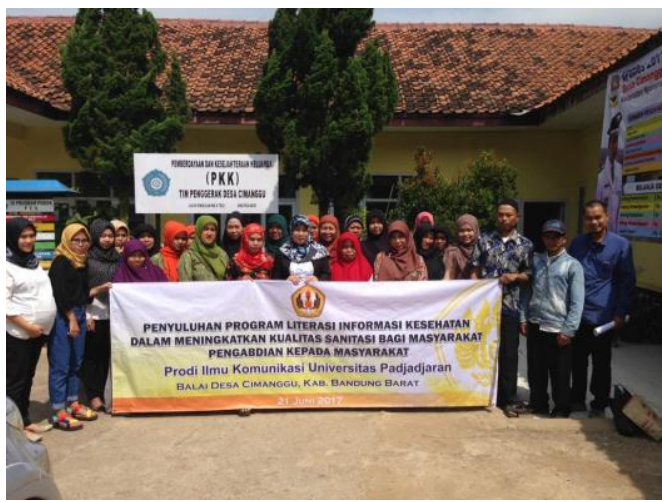

Gambar 1.4 Foto bersama Tim PKM Prodi Ilmu Komunikasi skema PPM Prioritas Unpad bersama Peserta Penyuluhan di Kab.Bandung Barat

Rencana jangka panjang dari kegiatan penyuluhan ini adalah dengan menyebarluaskan materi penyuluhan ke desadesa lainnya di kab. Bandung Barat yang masih tertinggal, untuk menekan minimnya pemahaman tentang pentingnya memiliki literasi informasi kesehatan. Selain itu, diharapkan dapat terjalin kerjasama dengan Dinas Kesehatan untuk dapat memberikan informasi lebih lanjut tentang penyuluhan program literasi informasi kesehatan dalam meningkatkan kualitas sanitasi di desa Cimanggu, kab.Bandung Barat.

\section{Monitoring Dan Evaluasi Program}

Monitoring kegiatan penyuluhan "Program Literasi Informasi Kesehatan dalam meningkatkan Kualitas Sanitasi" telah dilakukan satu bulan setelah kegiatan penyuluhan dilakukan, yaitu dengan cara :

1. Mendatangi sekelompok peserta penyuluhan untuk mendapatkan feedback dan efek dari materi yang telah disampaikan.

2. Mendatangi kantor Desa, mewawancarai ibu Kepala Desa untuk mengetahui adanya tingkat partisipasi dari peserta penyuluhan tersebut. 
3. Evaluasi kegiatan penyuluhan dilakukan pada akhir kegiatan, yaitu setelah pelaksanaan monitoring dengan cara ;

a) Melihat animo atau antusiasme masyarakat mengikuti penyuluhan yang dapat dilihat dari kehadiran jumlah peserta, keaktifan peserta dalam berpendapat dan bertanya, serta antusiasme dan ekspresi mereka selama mengikuti penyuluhan.

b) Membandingkan sikap peserta penyuluhan sebelum mendapatkan dan setelah mendapatkan materi.

\section{PENUTUP}

\section{Kesimpulan}

Adapun hasil dari kegiatan Pengabdian Pada Masyarakat ini sebagai berikut:

1. Ibu-ibu PKK di desa Cimanggu, Kabupaten Bandung Barat ini sadar akan pentingnya memiliki pengetahuan tentang "Program Literasi Informasi Kesehatan dalam meningkatkan Kualitas Sanitasi dan Kebersihan Lingkungan di kaki Gunung Burangrang, kab.Bandung Barat.

2. Ibu-ibu PKK di desa Cimanggu Kabupaten Bandung Barat ini secara aktif ikut terlibat dalam setiap diskusi mengenai pengalaman mereka tentang sanitasi dan kebersihan lingkungan di kaki Gunung Burangrang, Kab.Bandung Barat.

3.Para peserta penyuluhan PKM ini sangat antusias dan proaktif dalam memberikan tanggapannya tentang program literasi informasi kesehatan. Mereka sangat mendukung kegiatan penyuluhan ini. Selama ini, mereka merasa tidak melek informasi, dan mereka sadar bahwa memiliki literasi informasi yang baik itu sangat mendukung keberhasilan pembangunan di Indonesia, khususnya di bidang kesehatan. Penyuluhan ini memberi tolak ukur tentang kemampuan para ibu PKK dalam memahami literasi informasi kesehatan.

\section{Saran}

Adapun saran yang ingin diberikan yakni perlu diselenggarakannya penyuluhan program literasi informasi kesehatan yang terus berkelanjutan demi menunjang Sustainable Development Program Government (SDGs), khususnya dalam meningkatkan kualitas sanitasi dan kesehatan lingkungan di Indonesia yang masih rendah.

\section{UCAPAN TERIMAKASIH}

Artikel ini merupakan karya ilmiah yang ditulis berdasarkan hasil kegiatan PPM Prioritas tahun 2017(Pengabdian Pada Masyarakat) Universitas Padjadjaran, skema Mono Tahun, yang telah didanai oleh pihak DRPMI Universitas Padjadjaran ini dilakukan di kaki Gunung Burangrang, Kab.Bandung Barat. Oleh karena itu, penulis ingin mengucapkan terimakasih yang setulustulusnya atas dukungan dan bantuan kepada :

1.Prof.Dr.med.Tri Hanggono Achmad, dr.,Rektor Universitas Padjadjaran

2.Rizky Abdullah, S.Si., Apt., Ph.D, Direktur DRPMI Universitas Padjadjaran

3.Dr.Dadang Rahmat Hidayat, S.H, S.Sos, M.Si, Dekan Fakultas Ilmu Komunikasi Universitas Padjadjaran

4.Dr.Trie Damayanti, M.Si, Manajer Riset, Inovasi, dan Kerjasama Fakultas Ilmu Komunikasi Universitas Padjadjaran

5.Dr.Purwanti Hadisiwi, M.Exced, Ketua Program Studi Ilmu Komunikasi Fikom Universitas Padjadjaran

6.Kepala Desa Cimanggu, kaki Gunung Burangrang, Kab.Bandung Barat beserta staffnya 


\section{DAFTAR PUSTAKA}

Berry, Dianne. (2007). Health Communication Theory and Practice. Open University Press, Mc Graw Hill Education: England.

Depkes RI. (2013). Riset Kesehatan Dasar. Jakarta: Badan Penelitian dan pengembangan Kesehatan Kementrian Kesehatan RI.

European Health Literacy Consortium. (2013). Health Literacy (HLS-EU)

Nielsen-Bohlman, Lynn, editors .(2004). Health Literacy, A Prescription to End Confusion, Institute of Medicine. The National Academic Press: Washington DC

Nutbeam, D. (2000) Health Literacy as A Public Health Goal : A Challenge for
Contemporary Health Education and Communication Strategies Into The

21 st Century. Oxford J Med Health Promotion Int, 15(3): 259-267.

United Nations Educational, Scientific, and Cultural Organization (UNESCO).

(2008). Information for All Programme (IFAP): Towards Information Literacy Indicators., diakses online melalui http://www.uis.unesco.org/template/pd f/cscl/InfoLit.pdf.

WHO/UNICEF. (2010). Progress on Sanitation and Drinking-water: 2010 Update. Geneva: WHO 2010.

Zarcadoolas.C, Pleasant.A.F, Greer. D.S. (2006). Advancing Health Literacy, A ramework for Understanding and Action. JohnWiley \& Sons, Inc: CA.

http://www.unicef.org, diakses pada 2 Juli 2017 Pukul 14:20 WIB 